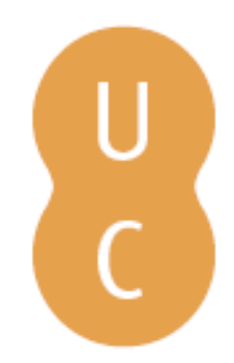

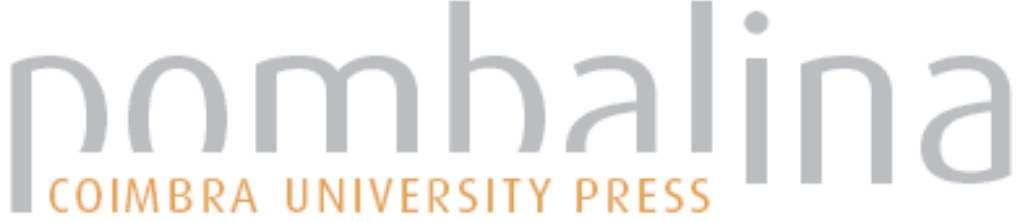

\section{O impacto da cavalaria romana na paisagem}

\author{
Autor(es): $\quad$ Ferreira, João Costa
}

Publicado por: Associação Portuguesa de Estudos Clássicos; Centro de Estudos

URL

persistente: URI:http://hdl.handle.net/10316.2/31549

DOI: $\quad$ DOI:http://dx.doi.org/10.14195/978-989-8281-69-2_10

Accessed : $\quad$ 26-Apr-2023 14:19:06

A navegação consulta e descarregamento dos títulos inseridos nas Bibliotecas Digitais UC Digitalis, UC Pombalina e UC Impactum, pressupõem a aceitação plena e sem reservas dos Termos e Condições de Uso destas Bibliotecas Digitais, disponíveis em https://digitalis.uc.pt/pt-pt/termos.

Conforme exposto nos referidos Termos e Condições de Uso, o descarregamento de títulos de acesso restrito requer uma licença válida de autorização devendo o utilizador aceder ao(s) documento(s) a partir de um endereço de IP da instituição detentora da supramencionada licença.

Ao utilizador é apenas permitido o descarregamento para uso pessoal, pelo que o emprego do(s) título(s) descarregado(s) para outro fim, designadamente comercial, carece de autorização do respetivo autor ou editor da obra.

Na medida em que todas as obras da UC Digitalis se encontram protegidas pelo Código do Direito de Autor e Direitos Conexos e demais legislação aplicável, toda a cópia, parcial ou total, deste documento, nos casos em que é legalmente admitida, deverá conter ou fazer-se acompanhar por este aviso.

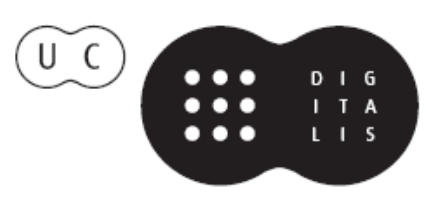




\section{Espaços e Paisagens}

Antiguidade Clássica

e Heranças Contemporâneas

Vol. III

Francisco Oliveira, Jorge Oliveira e Manuel Patrício

IMPRENSA DA UNIVERSIDADE DE COIMBRA 


\title{
O IMPACTO DA CAVALARIA ROMANA NA PAISAGEM
}

\author{
JoÃo Costa FerReIRA \\ Médico Veterinário \\ Ex-director da Coudelaria de Alter
}

\begin{abstract}
This presentation aims to demonstrate how the Romans, seeking to use the potentialities of the horse to the full, caused the first "global" impact on the landscape - the road network.
\end{abstract}

Keywords: highway, Roman cavalary, Space Shuttle

Palavras-chave: cavalaria romana, rede viária, Space Shuttle

O maior, ou menor, impacto de uma rede viária resulta, necessariamente, do bom critério do seu traçado. Os romanos, tanto quanto se sabe, concebiam o traçado das suas estradas não fruto de projectos, vistos e revistos, em face da contestação de comissões de moradores, de proprietários, de ambientalistas, de arqueólogos e outros fundamentalistas, com o patrocínio de Bruxelas, mas do percurso que um burro fazia desde o ponto onde se pretendia chegar, ao ponto de partida onde o referido burro tinha o seu palheiro.

Repare-se que este modo de fazer não é tão tolo como parece, pois o burro, que de burro pouco tem, sendo na escala de inteligência das espécies domésticas o segundo, logo a seguir ao cão, optaria por um traçado que seria o melhor compromisso entre o percurso mais curto entre dois pontos e a maior horizontalidade, por razões de economia de esforço. O burro procuraria o piso de melhor consistência, pois, por força da sua pequena base de sustentação, é de todos os animais o que exerce maior força de pressão sobre o terreno, o que o torna muito vulnerável aos terrenos que mais atolem. $\mathrm{O}$ burro, por ser um animal tímido, que tem na fuga a sua principal defesa dos predadores, escolherá o melhor percurso, de onde os possa avistar a tempo de deles fugir.

Interpretando estas particularidades para a óptica do construtor, haverá que considerar que era do seu interesse óbvio o percurso mais curto e de maior horizontalidade, assim como a qualidade do piso, e também o é pela evidente economia da construção da estrada. O percurso condicionado a "ver antes de ser visto", ou a tempo de fuga, também se coadunava com o interesse dos exércitos romanos em marcha, pois estes, pela supremacia que detinham, o 
que mais lhes interessava não era surpreender as forças inimigas, mas não ser surpreendido por elas.

A relação do romano com o cavalo assumiu formas muito peculiares que importa referir, para que se possa entender o que foi a sua utilização.

A cultura hípica foi coisa importada, com a sua divulgação a fazer-se a partir das classes ricas, que dela se serviu como modo de diferenciação social. Nunca foi de prática popular como o foi noutras zonas - Lusitânia, Numídia, entre os Partos, que tanto tiveram a ver com a história militar de Roma, estando na base de alguns dos desaires mais rotundos das suas legiões.

Outras razões haverá para justificar a maior aptidão dos povos dessas regiões para a equitação, ao invés dos romanos, mas foi, estamos em crer, por aqueles praticarem uma economia pastoril, com maior ou menor transumância e/ou nomadização dos gados, cujo sucesso em muito dependia da utilização do cavalo. Estes factores foram determinantes para a vulgarização da utilização do cavalo nesses povos. É nossa convicção que esta capacidade de uso determinou a domesticação do cavalo. O uso militar do cavalo foi consequência das suas capacidades reveladas na utilização civil e nunca o contrário, como é frequente ser referido.

O cavalo assumiu em Roma particular relevância na tracção, no transporte de pessoas e bens, pela velocidade que permitia, versus alternativa existente, o boi.

Aimportância estratégica da rapidez das comunicações na vida do Império, por imperativos de ordem económica, social ou militar, vá-se lá saber se ditames de ordem política de tipo Keynesiano, também não tiveram a sua influência, ou simples imposição do lobbies dos construtores, que levaram à construção de uma formidável rede viária, de cujo impacto na paisagem não nos chegou notícia de contestação ambientalista.

Muitos desses troços chegaram aos nossos dias, mas de principal relevância são as obras de arte, de uma engenharia prodigiosa, que permite ainda hoje a sua utilização, algumas ainda integradas na actual rede viária, suportando cargas que estariam bem longe das previsões mais acauteladas dos seus engenheiros.

Se a capacidade de carga dessas pontes ultrapassava, em muito, as necessidades da época, por feliz acaso, ou erro de cálculo, tornou-as adequadas às cargas de hoje. Já a dimensão da via (largura) se revelou correcta para os dias de hoje, não sendo necessário soltar a imaginação para justificar tal facto, pois que o foi pela simples razão de a base de cálculo ser a mesma de hoje em dia.

As nossas viaturas automóveis são fruto de uma evolução que teve como base o carro de cavalos, os trens, com quem durante muito tempo partilharam as estradas e pontes.

Até parece redundante afirmar-se que os carros de cavalos estavam dimensionados pelo cavalo no que aqui mais importa - a largura, cuja medida foi ditada pela soma da largura da garupa de dois animais lado a lado, 
a parelha, que constitui a unidade tipo do engate, fazendo-se a sua variação por múltiplos desta unidade em tandem.

A diferença de tamanho do cavalo de então para os dias de hoje é significativa, penso aliás que é no pequeno tamanho do cavalo daqueles tempos que reside a explicação para o não uso de estribos pelos cavaleiros romanos, mas essa diferença não é suficiente para invalidar a base de cálculo da largura das vias, de modo a permitir ainda hoje a sua utilização plena.

A maior propensão do romano pela utilização do cavalo na tracção do que na sela, julgo que fica bem evidenciada pelos espectáculos de base competitiva, também ditos desportivos, pelos quais nutria paixão exaltada. As corridas de cavalos de velocidade pura faziam-se não com o cavalo montado, como hoje, mas com o cavalo tirando um carro, as famosas bigas ou quadrigas.

Os hipódromos, formidáveis construções feitas especificamente para as corridas de carros de cavalos, não são mais que uma pista dividida no seu eixo maior por uma simples separação, a spina, que obrigava nos seus topos a voltas de 180 graus tão apertadas quanto possível, feitas à velocidade que o virtuosismo do auriga permitisse. Esta manobra, que nos merece todo o respeito pela dificuldade que encerra, é imaginável ser feita por uma equipagem, mas já não o é por um cavalo montado e sem estribos lançado a galope, em competição, em grupo e debaixo dos incitamentos da multidão.

Nas pistas dos hipódromos de hoje as curvas não têm um raio inferior a cinquenta metros e as corridas são feitas com os cavalos montados, não há corridas de velocidade pura com cavalos engatados.

Importa referir que o cavalo ibérico (o nosso puro-sangue Lusitano) é tido como o cavalo mais capaz para conseguir efectuar voltas apertadas, fruto da sua anatomia, de que resulta um equilíbrio muito próprio. Talvez esteja aqui a explicação para o sucesso, em Roma, dos cavalos de Torre de Palma, sucesso bem assinalado nos mosaicos multiplamente conhecidos.

Na evolução do transporte, ao surgir a máquina a vapor, como bem refere Richard J. Salomon no livro The Gordian Knot, editado em 1999, a bitola (distância entre carris) esteve condicionada à dimensão da via, que, por sua vez, condicionou todas as obras de arte que a rede de caminhos de ferro obrigou a construir. Daqui resultou nomeadamente pelo gabarito, vão e altura dos túneis, um condicionalismo no dimensionamento dos foguetes externos do Space Shuttle, os SRB, Solid Rocket Booster, que tiveram que ser alterados quando foi tomada a decisão de os fazer deslocar, por via-férrea, do local de fabrico, em Utah, para Cabo Canaveral. Assim sendo, assume-se que a garupa do cavalo romano projectou a sua influência desde a largura das carruagens à largura das vias e pontes romanas, que se mantiveram em uso por toda a Idade Média e Moderna, e que os projectistas dos caminhos-de-ferro, no século XIX, se sujeitaram a essa medida, que condicionou, igualmente, a dimensão dos nossos automóveis; e mesmo a conquista do espaço não se furtou à bitola da garupa do cavalo romano. 
Anexos:

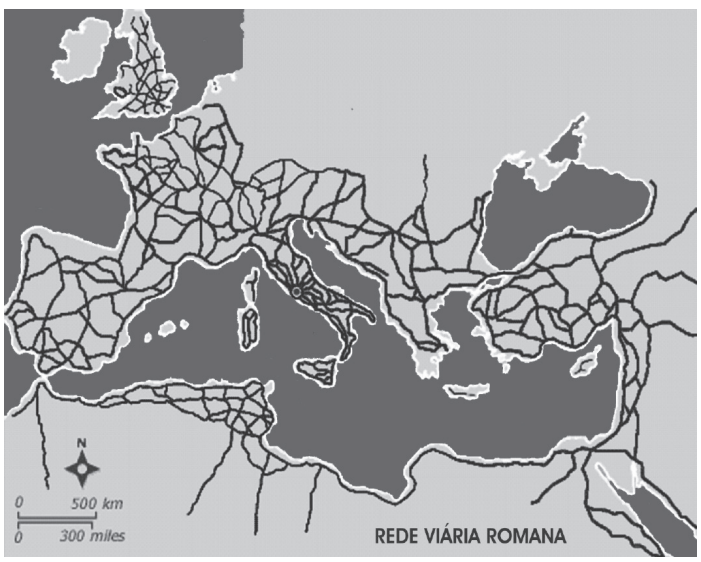

Fig.1. Principal rede viária romana

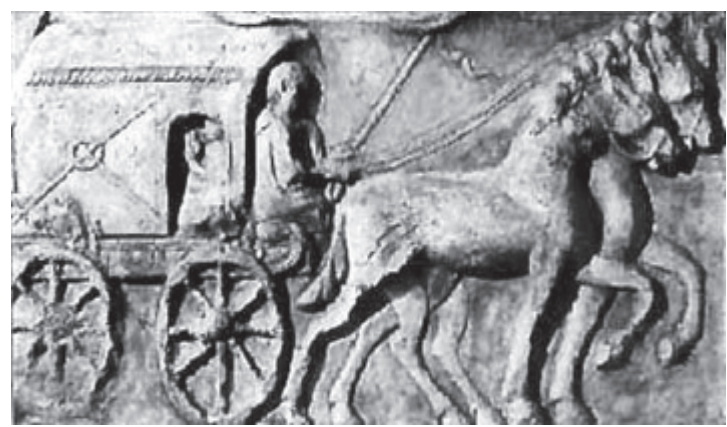

Fig.2. Carro de cavalos romano

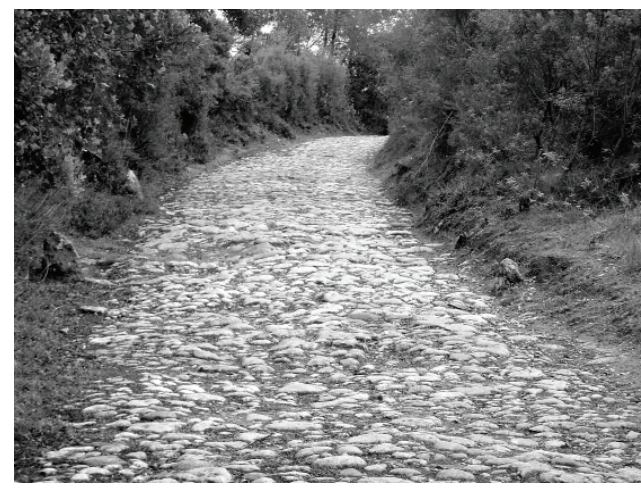

Fig.3. Estrada romana 


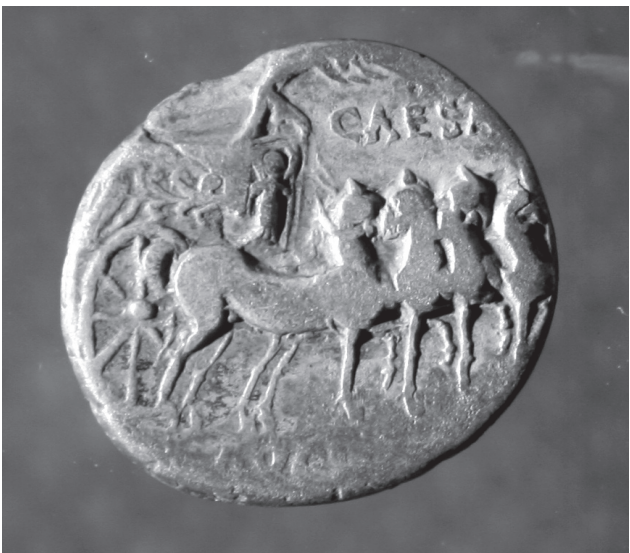

Fig.4. Quadriga em moeda romana (Coudelaria de Alter)

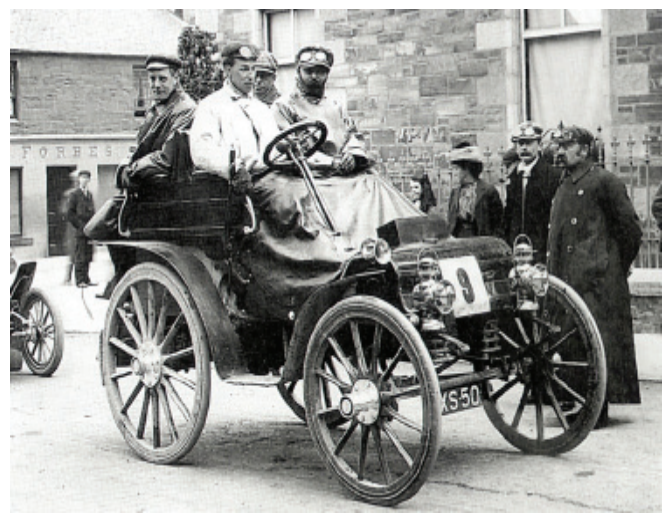

Fig.5. Automóvel de finais do séc. XIX

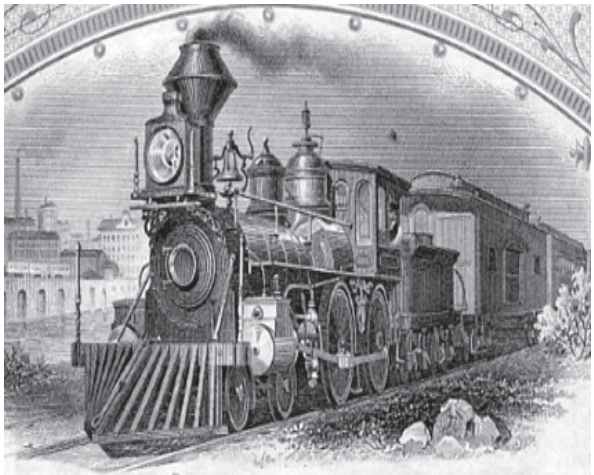

Fig.6. Comboio de finais do séc. XIX 
João Costa Ferreira

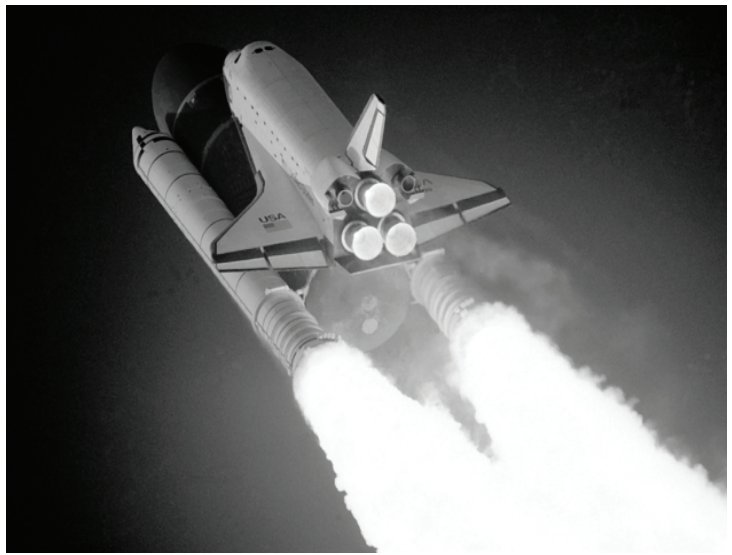

Fig.7. Space Shuttle

(Créditos fotográficos das Fig. ${ }^{\circ} 1$, 2, 5, 6, 7: www.picturehistory.com) 